\title{
IMIA - A 40 Year Organizational Overview*
}

\author{
S.A. Huesing \\ IMIA, the International Medical Informatics Association, Edmonton, Canada
}

\begin{abstract}
Summary
Objective: To chronicle the history of IMIA, the International Medical Informatics Association, from 1967 to 2007.

Method: Describing the key events and accomplishments through the terms of office of its presidents.

Results and Conclusions: The IMIA of today has been shaped by the individuals within it. Those influencing and guiding IMIA from its origins to today include its national representatives, Board and

Presidents, working group members, regional liaisons, and Medlnfo attendees.

\section{Keywords}

Medical informatics, health informatics, biomedical informatics, International Medical Informatics Association, IMIA

\section{Geissbuhler A, Haux R, Kulikowski C, editors. IMIA Yearbook of Medical Informatics 2007. Methods Inf Med 2007; 46 Suppl I: 186-91}

\section{Preface}

As the IMIA family comes together under the umbrella of MedInfo 2007, we celebrate not only the achievements and knowledge that the participants will present and learn from; we also will celebrate IMIA's 40 year legacy - a legacy that is the cumulative sum total of the contributions (academic, scientific organizational and administrative) of literally thousands of volunteers. The IMIA of today has been shaped by the individuals within it. Those influencing and guiding IMIA from its origins to today include its national representatives, Board, working group members, regional liaisons, and MedInfo attendees. Over the years, the commitment to IMIA has been remarkable; some individuals "present since the creation" are still active within the organization- on committees and within the various working groups.

With the continued evolution and recent diversification of informatics, IMIA has seen differing generations of professionals join its numbers. As well, with the sharply increasing political interest in the eHealth revolution, IMIA has embraced new and emerging nations into the "family". This is a testament to those early pioneers whose vision of informatics as an integrate component of the health of the word's population has proven to be the "right" direction.

\footnotetext{
* This brief history has been heavily plagiarized from the History on the IMIA website [1] and other documentation. Many thanks to Marion Ball who authored much of the text on the site.
}

As a volunteer organization, IMIA has been shaped by its presidents and their boards in their leadership roles [1-2]. All have left their mark on the organization. Through the years, IMIA has grown and changed. Today, through its strategic planning process "Towards IMIA 2015" under the leadership of Dr. Nancy Lorenzi, IMIA president, the Board and the membership are taking new and innovative measures to ensure that IMIA plays a vital and vibrant key role in representing and shaping health informatics world wide [3].

We will chronicle the history of IMIA by describing the key events and accomplishments through the terms of office of its presidents. References, in particular on the proceedings of the mentioned Medinfo congresses and on the IMIA Yearbooks can be found in [4].

\section{Starting the Movement}

\section{François Grémy, France, IMIA President 1968-1975}

In 1967, François Grémy established TC4, a Technical Committee within the International Federation for Information Processing (IFIP). As first chairman and moderator of TC4, Gremy is considered to be the first President of its renamed and refocused successor, the International Medical Informatics Association (IMIA).

The role of IFIP-TC4 in bringing together early health-informaticians cannot be underestimated. Although TC4 was composed in large part of computer 
professionals interested in medical applications, Grémy recruited the first generations of IMIA officers and members from the medical and health care communities. Intellectually as well as organizationally, IFIP-TC4 was the true predecessor of IMIA. During Gremy's term, the first global conference on Medical Informatics (1974 MEDINFO in Stockholm) took place.

MedInfo 1974: Stockholm, Sweden

\section{Transforming the Organization}

\section{Jan Roukens, The Netherlands, IMIA President 1975-1980}

The second President of IMIA, Jan Roukens was deeply involved with the transition from IFIP-TC4 to IMIA. Increasingly, medical computing became a field where the computer and medical worlds met, and IMIA was established to meet the needs of professionals from both.

National member societies from around the globe were offered seats on the board and membership in the General Assembly.

The European Federation for Medical Informatics (EFMI) was established to accommodate regionalization by allowing its member societies to "move" immediately into IMIA, giving IMIA credibility from the beginning.

IMIA was formally established by IFIP in 1979, with specific bylaws giving it measure of autonomy. Roukens was elected President. "In retrospect," he muses, "it seems quite incredible that all of this was in fact realized in a period of little more than two years!" Speaking of key players in those early days, he remarks, "Oh, there were so incredibly many. I could talk names for half hour without interruption. Thinking back to those days and all those people gives a warm feeling, and of richness without end."

According to Roukens, IMIA succeeded by giving its members a platform, an intellectual framework, for discussion. "Its domain of discourse is scientific and essentially liberal."

MedInfo 1980: Tokyo, Japan

\section{Building an International Membership}

\section{David B. Shires, Canada, IMIA President 1980-1983}

David B. Shires assumed the IMIA presidency in 1980, one year after the transition from TC4. During his term, Shires reached agreements with the regional group for Central and South America, known as IMIA-LAC (Latin American Countries), and the most populous country in the world, the People's Republic of China (PRC), making them active participating members in IMIA.

Shires saw IMIA as a family, within which "the then USSR and Eastern Bloc countries as well as other countries such as Cuba, could indulge in animated and mutually productive discussions with their western counterparts, with each respecting the other's political differences." IMIA worked to become meaningful to developing countries and forged new bonds with the World Health Organization.

In 1992, Shires reflected that "IMIA has grown considerably in reputation, recognition and credibility in the ten years since I left the presidency, largely due to the continuing hard work of Presidents Peterson, Kaihara and Willems."
Today IMIA reflects Shires' goal for his presidency in its international constituency, which goes "beyond the Europe-North America-Japan axis to a much greater world vision."

Today, the IMIA family includes a newly invigorated African region (HELINA) and is well on its way to facilitating the establishment of a Middle East Region.

MedInfo 1983: Amsterdam, The Netherlands

\section{Surviving Financial Crisis}

\section{Hans Peterson, Sweden, IMIA President 1983-1986}

In 1983, after three years as president elect, Hans Peterson became president of IMIA. "What I remember best", he says, "is that there was no money." Medinfo 83 had diminished already limited funds, and money was simply not available for what was needed for Medinfo 86 and subsequent activities. IMIA's officers ended up providing IMIA with free services, from printing and stationery to mailing and telephones.

Grants to working conferences were impossible, and IMIA's officers had to spend almost all their time on finances. The final blow came when IMIA closed its permanent secretariat in Amsterdam and its small remaining treasury vanished. The bottom line was "very little time for accomplishments and achievements. The goal was to survive."

Now, after completing his 18 th year as national representative for Sweden in 1993, Peterson continues to work for the recognition and acceptance of Medical Informatics. In his view, growing decentralization makes standardization critical. For Peterson, "an international body free from political and govern- 
mental influence is absolutely necessary. In this body we have to cooperate also with the industry and get a mutual understanding that cooperation is the only way out."

MedInfo 1986: Washington, USA

\section{Coping with Political Disruption}

\section{Shigekoto Kaihara, Japan, IMIA President 1986-1989}

From 1986 to 1989 Shigekoto Kaihara confronted problems that were uniquely global. So was the resolution he succeeded in effecting. He had played a key role in accepting a strong proposal from the People's Republic of China for Medinfo. For Kaihara, a Beijing meeting would demonstrate the relevance of Medical Informatics to developing countries as well as to developing nations. The theme of the conference, Informatics in Support of Global Health, reflected both IMIA's intentions and the input of the World Health Organization.

As fate would have it, Kaihara was in Beijing in early June, meeting with the Chinese organizing committee, when the world was jolted by the news of the events in Tien-an Men Square. Once back in Japan, he faced faxes from around the world and fears whether "IMIA as an organization would survive." The final resolution was to hold a two-part Medinfo. Medinfo Beijing rewarded the work and the eagerness of its organizing committee, and Singapore's K.C. Lun applied his extraordinary ability and efficiency in arranging Medinfo Singapore. Both MedInfo's succeeded.

Also during his term, Kaihara strengthened IMIA's scientific linkages with IFIP and gained administrative independence for IMIA. Today, he believes,
"There is no comparable international organization in the field of Medical Informatics."

\section{MedInfo 1989: Singapore/Beijing}

\section{Preparing for IMIA's Future}

\section{Jos L. Willems, Belgium, IMIA President 1989-1992}

The national representative to IMIA for Belgium since 1978, Jos Willems, accepted the position of IMIA President Elect at Medinfo 86 and served through Medinfo 92 in Geneva, Switzerland. According to Willems as he concluded his term, "The major challenge of the presidency is to keep IMIA's activities going. The major task is to stimulate people. The organization is up to now entirely run by volunteers. IMIA needs a paid Executive Secretary and Secretariat if the organization wants to grow." Among his achievements as President was the publication of the first Yearbook of Medical Informatics for Medinfo 92. This volume was intended to "Stimulate our field and encourage investigators to produce work of high scientific quality and medical relevance." IMIA was also received official recognition as Non-Governmental organization (NGO) to the World Health Organization (WHO).

Leaving his office of president, Willems recalled the social activities of the Board with great pleasure and credited IMIA with broadening his professional horizons "as a result of the many international contacts in different continents."

\section{MedInfo 1992: Geneva, Switzerland}

1992 Yearbook of Medical Informatics: Advances in an Interdisciplinary Science van Bemmel, Jan H., McCray, Alexa T., Eds. Schattauer, Stuttgart.

\section{Moving from Theory into Practice}

\section{Marion Ball, USA, IMIA President 1992-1995}

When Marion Ball assumed the presidency in 1992, she came with a new vision set by the IMIA Board in its strategic planning. She was intent upon making IMIA a "bridge" organization with strong ties to other professional associations as well as institutions in healthcare and higher education. To move from theory to practice, she worked with the IMIA Board to launch a new institutional membership category that would strengthen IMIA's ties not only to these groups but also to the vendor and consulting worlds. By mid 1993, there were twenty institutional members eager to participate in events around the globe, from the United States to Japan and in between.

One of the first challenges to her presidency came in early 1993, when Brazil was forced by economic and political uncertainties to withdraw as site for Medinfo 95. At the request of the Board, Canada, which had earlier sought the honor of hosting Medinfo, quickly stepped into the breach. As plans for Medinfo moved forward, Ball worked on issues vital to IMIA's future, establishing a stable financial base and a new infrastructure for the new IMIA.

Initiatives targeted creating a regional IMIA presence in the Asia Pacific Region (APAMI). Actions were taken to strengthen IMIA working group meetings one of IMIA's enduring and enriching activities by cosponsoring them with other professional and institutional member groups. 
In her presidency, Ball sought to broaden IMIA's vistas and incorporate new areas of interest by encouraging new working conferences and groups to address such topics as organizational development, health evaluation, pharmaco-informatics, technology assessment, clinical computing, and telemedicine.

\section{MedInfo 1995: Vancouver, Canada}

1993 Yearbook of Medical Informatics: Sharing Knowledge and Information 1994 Yearbook of Medical Informatics: Advanced Communications in Health Care

1995 Yearbook of Medical Informatics: The Computer based Patient Record

van Bemmel, Jan H., McCray, Alexa T., Eds. Schattauer, Stuttgart.

\section{Towards a Sustainable Infrastructure}

\section{Otto Rienhoff, Germany, IMIA President 1995 - 1998}

The change to a global information society has been pushed in many ways by governments and international organizations. As a result various initiatives exist which reflect the mission, purpose, political background, and market interest of the backing institution. Telematics in Health and Telemedicine have been drawing enormous attention modulated by national health care structures and finances.

A major achievement of the 8th presidency was the establishment of a sustainable electronic infrastructure for IMIA (www.imia.org) managed by Thomas Kleinoeder. Sustainability in IMIA's context means that the electronic infrastructure had to be set up to serve members with such different resources as isolated persons in Africa and hightech Universities in the US. It means to establish services which can be financed by IMIA without dependencies on third parties, which guarantee compliance with IMIA's aims, and can cope both with the strong and the weak sides of an international volunteer organization. It will be the task of the coming years to elaborate this infrastructure and to learn to manage virtual working groups and conferences with it.

The definition of the role of an Executive Director for IMIA in the context of a continuous and stable secretariat function was another major achievement. Again the considerations apply as mentioned above. The process reached its first major success with the election of Steven Huesing (Canada) as IMIA's first Executive Director at the 1997 General Assembly in Sydney Australia. Learning from experiences with the Electronic Services and with MEDINFO ' 98 in Korea the process for identifying an appropriate candidate for the first full three-year term could be started in 1998. Further, in context with moving towards a stable infrastructure for IMIA, the establishment of Standard Operating Procedures was initiated as a first step in maintaining continuity and codifying Board and General Assembly policy and the processes whereby they are carried out. The establishment of an African Region (HELINA) was started during the regional conference in Midrand, South Africa in 1996, followed by a Frenchspeaking regional conference in Abidjan in 1998. S. Isaacs, Cape Town, served as first coordinator.

\section{MedInfo 1998: Seoul, Korea}

1996 Yearbook of Medical Informatics: Integration of Information for Patient Care
1997 Yearbook of Medical Informatics: Computing and Collaborative Care 1998 Yearbook of Medical Informatics: Health Informatics and the Internet

van Bemmel, Jan H., McCray, Alexa T., Eds. Schattauer, Stuttgart.

\section{Entering the Twenty-First Century}

\section{Jan H. van Bemmel, The Netherlands, IMIA President 1998-2001}

One of the missions of the 9th President of IMIA was to foster the continuum of IMIA's ongoing evolution as a sustainable and independent Professional organization. Within that context, IMIA's primary communications vehicle, the IMIA web site, www.imia.org was moved from its hosting site at Goettingen University to the offices of the IMIA Secretariat. In the process, the site underwent significant technological enhancement through the use of a dynamic data base greatly enhancing the site's capability to communicate and share information among IMIA members and the public at large as well as providing the means to showcase IMIA's working groups and National and Institutional members. The Executive Director, Steven Huesing, was re-elected for a three-year term in 1998 and again for a further three-year term at the General Assembly in London in 2001.

The editorial aspects of the IMIA yearbook, managed by the staff at Erasmus University since the yearbook's inception in 1992 (Jan H. Van Bemmel and Alexa McCray, Editors) were successfully transferred to the University of Heidelberg with Dr. Reinhold Haux (IMIA Vice President of Services) and Casimir Kulikowski assuming the roles 
of Editors. Inherent in this change was the use of IMIA website data for the IMIA-related pages of the Yearbook. Van Bemmel was unrelenting in the pursuit of IMIA's role as a "Bridge" organization both within an inter-organizational context and within the broader context of the Professional aspect of IMIA's aims. In the former case, he was successful in negotiating an affiliation agreement with the International Federation of Health Records Organizations (IFHRO). Within the professional context, the concept of the "Virtual University", led by Evelyn Hovenga, Queensland University (Australia) took root and flourished. As a result of these initiatives, IMIA's Institutional members, both Academic and Corporate, grew to record numbers. In addition, IMIA's efforts to include scientists, researchers and educators in developing countries were extremely successful in that Correspondent memberships increased dramatically.

Prof. Van Bemmel strongly believed in "Visibility" and through his personal actions and contributions greatly enhanced the image of IMIA around the world. During his term he delivered numerous keynote addresses at the meetings of IMIA member societies and delivered lectures at many International Congresses. In his role as IMIA's Statesman, he strived to organize an IMIA-sponsored medical/ health informatics conference in the Middle East; unfortunately, because of the political developments at the time, this was not realized.

\section{MedInfo 2001: London, United King- dom}

1999 Yearbook of Medical Informatics: The Promise of Medical Informatics 2000 Yearbook of Medical Informatics: Patient-centered Systems van Bemmel, Jan H., McCray, Alexa T., Eds. Schattauer, Stuttgart.

2001 Yearbook of Medical Informatics: Digital Libraries and Medicine

Haux, Reinhold, Kulikowski, Casimir, Eds. Schattauer, Stuttgart

\section{No stranger to crisis management}

\section{KC Lun, Singapore, IMIA President 2001-2004}

$\mathrm{KC}$ Lun is no stranger to crisis management. Following the Tien-an Men incident in the People's Republic of China in June 1989, KC Lun helped IMIA to relocate the international meeting of MEDINFO '89 from Beijing to Singapore. Within 6 months, he made it possible for MEDINFO '89 Part II (the international meeting) to be held at the Raffles City Convention Centre in Singapore and turned it into one of the most profitable MedInfo's for IMIA.

In September 2001, he became the second Asian to become the IMIA President. During his 3-year term, KC steered IMIA through a period of global economic slowdown to end his term of office with an operating budget surplus and probably the most financially successful MEDINFO to-date in San Francisco in September 2004. In recognition of his leadership, he was presented a plaque by IMIA and made an IMIA Honorary Fellow at the closing ceremony of MEDINFO 2004 in San Francisco. Commenting on the recognition, KC Lun said, "I am pleased to have had the opportunity to serve IMIA and grateful for the friendship that I have made with colleagues from all over the world, dating back to 1986 when I first started this wonderful relationship with IMIA".
MedInfo 2004: San Francisco, USA

2002 Yearbook of Medical Informatics: Medical Imaging Informatics

2003 Yearbook of Medical Informatics: Quality of Health Care: The Role of Informatics

2004 Yearbook of Medical Informatics: Towards Clinical Bioinformatics

Haux, Reinhold, Kulikowski, Casimir, Eds. Schattauer, Stuttgart

\section{Strategy for the Future - Towards IMIA 2015!}

\section{Nancy Lorenzi, USA, IMIA President 2004 - 2007}

In the future there will be a world-wide systems approach for healthcare. Clinicians, researchers, patients and people in general will be supported by a system of information technology tools, processes and behaviors that make it easy to do the right thing, in the right way, at the right time to improve health care for all. This systems approach will incorporate and integrate research, clinical care and general public health. To achieve this future vision for the $21^{\text {st }}$ century healthcare and research it will require everyone being supported by informatics-based information systems. As the $10^{\text {th }}$ President of IMIA, Dr. Lorenzi has engaged the full membership of IMIA in a comprehensive strategic planning process to establish the role of IMIA in that vision of the future. At this juncture it is held that IMIA's role will be to provide leadership and expertise in health/medical informatics to the multidisciplinary health focused community and policy makers in order to enable the transformation of healthcare in accord with the world-wide vision to improve the health 
of the world population. IMIA will fulfill its vision by

- Being the informatics association through which the world's knowledge leaders come together to effectively and efficiently create, assemble, integrate, synthesize or assimilate intellectual knowledge that is required worldwide to advance medical/health informatics in its role of improving health and healthcare.

- Being the informatics association that effectively and efficiently connects people and the nations of the world to be able to accomplish the above purpose.

The IMIA General Assembly has approved the tenets of the plan and will be fully involved in its completion and execution.

Significant collateral effects of this planning process have already emerged as IMIA directs its resources to accomplishing the tactical objectives of the plan. The membership of the Academic institutional membership has grown to over 50 Academic institutions who now regularly meet as a group. HELINA
(African) Region has been energized and held a major conference in Mali followed by a meeting of 18 African nations; they have since established a constitution and the organizational framework to remain viable and active. Similarly, through the work of Hiroshi Takeda, VP Special Services, the Middle East region is on its way to being formulated with increasing membership from societies and institutions from that area of the world.

During her term, IMIA formalized its relationship with WHO and IFIP by appointing Liaison Officers to WHO (Antoine Geissbuhler and to IFIP (Hiroshi Takeda).

Most significant of her successes, is the openness and transparency that has characterized Dr. Lorenzi's presidency and leadership style.

\section{MedInfo 2007, Brisbane, Australia Biomedical Informatics for Sustainable Health Systems}

2005 Yearbook of Medical Informatics: Ubiquitous Health Care Systems
2006 Yearbook of Medical Informatics: Assessing Information Technologies for Health

2007 Yearbook of Medical Informatics: Towards Clinical Bioinformatics

Haux, Reinhold, Kulikowski, Casimir, Eds. Schattauer, Stuttgart

\section{References}

1. www.IMIA.org. Last accessed May $3^{\text {rd }}, 2007$.

2. Peterson HE. From Punched Cards to Computerized Patient Records: A Personal Journey In: Haux R, Kulikowski C, editors. 2006 IMIA Yearbook of Medical Informatics. Methods Inf Med 2006; 45 : S180-6.

3. Lorenzi N. Strategy in a fishbowl: an invitation to determine the shape of IMIA in 2015. Methods Inf Med 2006; 45:235-9.

4. Peterson HE, Hutter M. IMIA's Publication History. In: Geissbuhler A, Haux R, Kulikowski C, editors. 2007 IMIA Yearbook of Medical Informatics. Methods Inf Med 2007;46:192-6.

\section{Correspondence to:}

Steven A. Huesing, CMA

Executive Director,

IMIA, the International Medical Informatics Association

5782 - 172 Street NW

Edmonton, AB T6M IB4

E-mail: imia@shaw.ca

www.imia.org 